\title{
NATO looks at its science programme
}

THE Science Committee of the North Atlantic Treaty Organisation (NATO) is 20 years old and has been holding a large conference in Brussels to celebrate the birthday. Official delegations from the 15 member nations and various other scientists, administrators and hangers-on have been regaled with two and a half days of a curious blend of science, opinion and diplomatic niceties. Science in the research sense was disposed of in half a morning during which rather more than 300 pages of preparatory papers had to be digested and discussed; the remainder of the time was devoted to more general problems of science and technology and its relationship to society, international relations, education and demography, decision-making and so on. The technological centrepiece was a trans-Atlantic computer link-up which allowed the audience to see the broodings of a computer at Case Western Reserve University on world futures up to the year 2025 in four- and five-significant-figure glory with never an error bar in sight.

What is NATO doing in science? For nearly ten years of the alliance there was no science, at least at the civilian level. Then in 1956, after a backward glance at Article II of the North Atlantic Treaty, which spoke about "strengthening free institutions ... and promoting conditions of stability and wellbeing", the so-called "Three Wise Men" started to prepare the ground for scientific collaboration. There was at the time a certain unease at the state of the alliance, and also at the state of science (which the launching of the first sputnik in 1957 helped to bring into clear focus). Heads of government of the alliance agreed shortly thereafter that "the full development of our science and technology is essential to the culture, economy and political and military strength of the Atlantic community . . . we must build the established tradition of the universality of true science". In March 1958 the science committee first met. For 20 years it has been occupying itself with, amongst other things, supporting international fellowships, collaborative research grants and advanced study institutes. Last year it spent a little under $\$ 10$ million; in recent years its expenditure has been declining in real terms.

Now the things that people say about NATO's involvement in science are that an organisation that is ostensibly military has no business getting into civilian science, indeed will use this support as window-dressing; that the "universality of true science" is no respecter of frontiers and is as likely to require collaboration with the Soviet Union, Sweden, Japan or Australia as with another NATO country; and that not only are there many developed countries not in NATO, there are also a very large number of developing countries who are excluded from the benefits. In short, that a NATO science programme is a somewhat unnatural concept.

With which it would be very easy to agree if there were a large bureaucracy in Brussels, obsessed with protocol and the correct ordering of things. But somehow the science programme has managed really to foster interchanges, raise the standards of advanced education and simply enable more people to meet more people on a budget smaller than some individual research projects in member states. Whatever one's reservations may be about the geographical confines within which the programme has to work (the Advanced Study Institutes are not quite so confined) the fact remains that within these limits, the programme is a model for how international collaborative science can work. Partly the restricted scale helps, there is no doubt. And partly the very fact that distinguished scientists make up the committee is of great value.

There are, even so, questions that can rightly be asked after 20 years. One of them is the place of industry in the scheme of things. There were very few industrialists at the birthday celebrations-understandably so in view of the usual industrial concern that its own research be protected against prying eyes. But the sort of things that were talked about, and that will probably continue to be talked about in NATO circles, have a growing need of the industrial point of view. Another question is how defence science fits in. Up to the present NATO has scrupulously kept its civil science free from defence applications (except in so far as almost any subject of study can have its defence side). Although in many ways excellent, this policy adds to the isolation of the defence scientist whose opportunities to meet other scientists and talk about problems of common interest are in any case very restricted. A most important job for the NATO science committee could be to poke around the fringes of the security screen and see where there might be areas in which defence scientists could profitably be brought into more contact with their civilian counterparts.

Should "science" now be extended to include the social sciences? Several celebrants wondered aloud about such an increase in scope. The answer should surely be no. If there is good cause for NATO to foster the social sciences on an international basis, it were best that a new office with a separate budget be set up for the purpose. There will otherwise only be suspicion that the science programmes are being drained of resources to help establish the social sciences, and there is enough coolness across the natural science/ social science barrier as it is, without inviting more in this way. 